\title{
A Child's Encounter with the Devil: An Unusual Near-Death Experience with Both Blissful and Frightening Elements
}

\author{
Richard J. Bonenfant, Ph.D. \\ Gainesville, FL
}

\begin{abstract}
I describe the near-death experience (NDE) of a 6-year-old boy who encountered both the devil and God following a near-fatal car accident, and compare recent recollections of the event with those made four years earlier. I discuss the aftereffects of this experience, and review the findings of earlier studies of frightening NDEs.
\end{abstract}

$K E Y$ WORDS: near-death experience; children; frightening near-death experience.

More than ten years ago, Harvey Irwin and Barbara Bramwell (1988) published an account of the near-death experience (NDE) of a 50year-old woman, which began as a blissful experience but changed to a frightening one upon an unexpected encounter with the devil. Conversely, the subject of the present account is a 6-year-old boy, named Scott, whose NDE began as a frightening experience because of an initial encounter with the devil but which later progressed to a more pleasant one. Scott's experience is remarkable because of the richness of detail that has been retrieved from his account and because of the rarity of frightening childhood NDEs in the literature.

Richard J. Bonenfant, Ph.D., is a retired medical researcher with the Congenital Malformations Registry at the New York State Department of Health and an Adjunct Instructor in the Department of Computer Science at Sienna College in Loudonville, NY. Reprint requests should be addressed to Dr. Bonenfant at 6008 S.W. 86th Drive, Gainesville, FL 32608; e-mail: richard_bonenfant@email.com. 


\section{The Accident}

Scott's NDE began as the result of an automobile accident that occurred in front of his house on Saturday, June 10, 1995, when he was 6 years old. On this particular day, he had joined his mother and 9-year-old brother as they went to purchase an ice cream cone from a vendor who was touring their neighborhood. Almost immediately after being handed his cone, Scott darted out from behind the ice cream truck and was struck by a passing motorist. The impact caused Scott to make several aerial somersaults before landing on the pavement some 25 feet from where he had been struck. When his mother, Karen, ran over to her son's twisted torso, she found that he had no pulse. The following narrative was written by Karen approximately ten months after the incident:

...I heard the car slam into him, heard the deceleration of the engine and the squeal of its brakes as its driver stopped dead. There was nothing but silence as I watched the upper half of Scott's body arc away from the hood of the ear, 180 degrees different from the point of impact on the hood with the right side of his head, launching him into three complete somersaults in the air as he catapulted away from the car and up the street to my left about 25 feet. I was horribly fascinated by how limp he was, like a rag doll, with legs and arms all akimbo. He settled onto the pavement on his right side as if someone were laying him there: his feet first, then his torso, then his head. I was disconcerted by the fact that this all occurred in slow motion, in a macabre fashion; there was a real grace to it.

... Scott landed on his right side: his left arm was straight down, and underneath him; both legs were drawn up and were lying on top of his left arm, to the left his torso was turned sharply to the right as was his head; and his right arm was flung unnaturally across his chest. He had landed on his right side, but the force of impact with the ground had caused his hips to "bounce," and flip abruptly to the left side. I'm a hospice homecare nurse, and he looked like every dead body that I have ever seen: waxy-looking bloodless skin, unmoving, not breathing. I didn't know what to do; I am also CPR certified and was a CPR Instructor-Trainer at one time, but he looked so broken, I was afraid to touch or move him in a way that would allow me to perform rescue-breathing.

Scott's father, who had been inside their house at the time, witnessed most of the accident through the window. He immediately dialed the 911 emergency code and informed the operator of the location of the accident. Then he ran over to his son and cradled Scott in his hands whispering the phrase "I love you" in his ear over and over until the 
ambulance arrived. From the scene of the accident, Scott was taken to a hospital and placed in the intensive care unit, where he remained under observation until he came out of a coma and his vital signs had stabilized. Being a nurse, Karen took careful note of her son's injuries, which included a concussion, a right-sided basilar skull fracture, total perforation of the right ear drum, a fracture of the right pelvis, swelling of the right ear and head, extended oxygen deprivation, and lacerations of the head, hands, right arm and elbow, and feet.

\section{The Near-Death Experience}

When Scott regained consciousness in the intensive care unit some eight hours later, he told his parents about what he had experienced following the accident. Scott's account began with the realization that he could not avoid being struck by the car, followed immediately by the memory of the impact, which he described as being "punched" by the car. This trauma was followed by a bilocation of consciousness and an out-of-body experience. Scott remembered being in his body as it was struck, and he also recalled witnessing the entire accident from the vantage point of a nearby tree some 30 feet away. He recalled seeing his body making three somersaults in the air and then landing on the pavement. While observing the accident and its aftermath, he felt no pain whatsoever but was dismayed that he could not make himself heard or seen by his family members. He shouted to his brother several times to come "play" with him but to no avail. However, on one occasion following the accident when his brother Graham and his mother were going to the hospital, Graham reported that he had heard Scott call out to him "in his head," but that he had ignored the call because he could see Scott's body laying unconscious on the pavement. Scott remembered hearing his father saying "I love you" to him but he could not make his own reply audible to his father, and when he tried to hug his father, Scott's arms simply passed through his father's body. Apparently Scott was able to hear and see everything that was going on around him at the scene of the accident, but no one there except Graham was able to see or hear him.

Scott next found himself facing the entrance to a vortex-like tunnel in a "bad dark place." He described the tunnel as looking "like a tornado laying flat on the ground." As he was drawn into the tunnel Scott found himself face-to-face with the devil. The devil spoke to Scott in a deep, raspy voice saying, "You're bad," and made an attempt to grab 
him. At that point Scott was completely terrified. He subconsciously felt that the devil was trying to "suck" him away from God. Scott said that, in some way, he could feel a strong negative force emanating from the devil. Scott described the devil as being composed of rotting, putrid flesh, and covered with sores and slime. The devil projected the impression of a being who was both mentally and physically ill.

Scott did not recall how he was rescued from the clutches of the devil. He stated simply that he desperately tried to keep his faith in God. He believes that God rescued him but he cannot remember exactly how it occurred. Scott emphasized that he had no control over what was happening to him and compared the experience to being moved through the house of horror on a carnival ride. By whatever means, Scott next found himself being whisked through the tunnel toward a distant point of light. When asked about the characteristics of the tunnel, Scott could remember only that it seemed to contain the faces and voices of all those who had ever known and loved him.

Scott recounted that after emerging from the tunnel, he met his deceased uncle Russell, who had died only a short time before Scott's accident. Scott and his mother gave two different versions of the meeting with his uncle. Scott's mother remembered that in Scott's original account, he described his uncle Russell as being dressed in a gray suit. The uncle apparently never wore dress suits when alive, so it seemed strange that Scott would describe him this way. She later recalled that the uncle had been buried in a gray suit; that fact, however, was unknown to Scott. In a more recent description of the meeting with his uncle, Scott reported that his uncle was wearing the same bedclothes that he wore before his death, and that during their meeting, he was in bed covered with a sheet. Uncle Russell told Scott that he had been in a bad accident, but he was not to worry because everything would be okay. Scott remembered that during their conversation, his uncle had addressed him by his nickname, "Buddy."

In contrast to his initial terror, Scott next reported seeing a brilliant light that did not hurt his eyes. Scott felt a goodness and security emanating from the light, and within it, a presence that he described as God. He could not recall whatever transpired during this meeting with God. However, toward the end of the encounter, a separate light came from God. Scott felt that that lesser light was an angel. In a recent interview, Scott could not distinguish the form or gender of this light-being or angel. He recalled only that the light resembled a star on a Christmas tree. However, his mother Karen remembered that on 
one occasion following his release from the hospital Scott had told her that the angel's name was Susan.

The angel escorted Scott through a dark but open place in which he could still see things. When asked about the features of this dark realm, Scott replied that it was different from what we see "here." Scott felt that the memory of these features "went away" or was taken away after his experience.

The last scene Scott recalled was of being taken by the angel to what he called a "dungeon." When questioned about why an angel would take him to a dungeon, Scott replied that "dungeon" was probably not the right word to use. He said that "it was not a room filled with chains and straw like in the movies" but rather a "safe place" where the devil could not get at him. Scott recalled that this room was strongly built but had no doors or windows. It was also a "good dark place" and he felt the presence of a protective being, the angel, there with him. This imagery of the sanctuary was the last thing Scott remembered before regaining consciousness in the hospital.

\section{Further Details and Documentation}

Scott's account of his NDE was brought to my attention through the referral of a hospice worker. A set of questionnaires relating to an ongoing NDE study were sent to Scott's parents and upon completion they were returned to me. The unusual nature of the account was immediately evident. Since the questionnaires had been designed for a different purpose, I contacted Scott's parents to ask their permission to conduct a more extensive interview with their son, then 11 years old. Scott's parents were both caring and protective of their son's experience. During the investigation, they were able to provide me with much documentation, including a narrative of the NDE written by Scott on November 11, 1997, two years following the original incident, when he was 8 years old. They also provided a figure drawn by Scott a few days after he had been discharged from the hospital representing the devil that he encountered during his NDE. He explained to me that various parts of the drawing represented the devil's feet with hook-like claws; its hands shaped like skeletal claws; a greenish ooze similar to the slime that was emitted by the ghostly ogres in the television cartoon "Ghostbusters"; the devil's body covered with infected, scab-like, rotting flesh; and the devil's head described as 
being deformed and sickly looking. When Scott originally drew the devil's eyes, his parents noted that he mashed and twisted his marker which such force that he wore an opening through the paper he was drawing on. Scott added that the devil's voice sounded like a raspy version of Darth Vader's voice in the movie Star Wars, a sound coming from deep within the throat and being very coarse, like sounds made by someone who was deathly sick. The devil told Scott that he was "bad."

Scott's parents also provided me with a second drawing he had made a few days after he had been discharged from the hospital, representing the angel that escorted him to the safe, dark place after his encounter with God. There was little that Scott could recall about this particular drawing except that the head was the most important part, and that the yellow aura was drawn to convey both the light and goodness radiated by this entity.

In March 1999, I asked Scott if he would be willing to make new drawings of the devil and angel, with the intent of comparing his original drawing with those made from the perspective of a five-year vantage point. I gave Scott no specific instructions regarding the drawing. The newer drawing portrayed a far more conventional portrait of the devil's head, depicting only certain facial features, including red eyes, raised eyebrows, nostrils, and large, pointed teeth. Scott added words spoken to him by the devil, "Your [sic] bad!," implying that Scott's soul belonged to him. Scott's recent portrait of his angel escort included simply a sun-like object with a white core. As Scott had previously noted, this entity, "came from God, but was separate from Him." At this point in time only the impression of the angel's brightness remains.

Scott's mother also provided me with a schematic chronology of his NDE she had drawn in collaboration with her son. A brief summary of this pictorial chronology includes (1) bilocation of consciousness at scene of accident; (2) observing the accident from the location of a nearby tree; (3) his out-of-body experience, in which he was unable to hug father and to make himself seen or heard; (4) being in a "bad dark place" facing a tunnel; (5) the encounter with the "devil" after entering a vortex; (6) continued passage through the vortex; (7) meeting his Uncle Russell; (8) the encounter with the Light (God); (9) awareness of the presence of an angel; (10) being escorted by the angel to a "good dark place" (the "dungeon"); and (11) regaining consciousness in the hospital. 


\section{Discussion}

The term frightening, distressing, or hellish NDE refers to an experience in which the dominant theme of the event is that of fright, fear, and concern for one's safety and well-being. As early as 1981, Jim Lindley, Sethyn Bryan, and Bob Conley observed that frightening NDEs are sometimes part of a larger experience that often begins or ends on a positive note. In the case cited above, recounted by Irwin and Bramwell (1988), the experience began on a positive note but ended on a negative one. Scott's case is just the opposite. His NDE began with an abrupt encounter with the devil but proceeded to a vision of God. While the later elements of his experience were positive in affect, the dominant emotional outcome of the overall experience was anxiety over the possibility of another encounter with the devil.

Scott's parents reported that their son suffered from restlessness, anxiety, and nightmares for months following his NDE. Shortly after returning home, Scott moved from his own bedroom into that of his older brother Graham, where both brothers felt more secure. Scott also began to show an interest in religion and he voluntarily attended church services more frequently. The following evaluation of these aftereffects was offered by Scott's father:

...I would say that Scott had difficulties resulting from the NDE. However, he also, based on the experience, developed a spirituality rather sophisticated for someone his age. Before that, he really hated church and Sunday school, etc. Eventually afterwards, he became quite interested in spiritual matters and now says that he likes church, and often asks questions that I have to really mull over to answer for him.

For a short period of time following the NDE, it seemed that both Scott and his parents were experiencing symptoms of posttraumatic stress disorder. All four family members of the family began visiting a counselor to find out whether Scott's symptoms and its effect on their lives were a normal consequence of his accident. These visits proved to be reassuring because the counselor's evaluation of their situation was consistently positive.

Some researchers have suggested that the visions and images witnessed by NDErs during their experiences are largely the product of acculturation. That is, experiencers see what they expect to see. They argue that even children are exposed to a wide range of religious and cultural images that condition them to visualize similar imagery 
during their NDEs. Traditional images of devils and angels abound in the media. Angels are depicted as being human in form, often female in gender, dressed in white garments, with large, white, feathered wings on their backs, and glowing with unearthly beauty. Devils are also portrayed as being anthropomorphic but with pointed horns, large bat-like wings, and sometimes with a barbed tail. Other popular representations of the devil depict a satyr-like being who is human from the waist up and goat-like from the waist down. While such visual experiences may occur in some NDEs, they do not in Scott's case. Scott's description of the devil is quite unorthodox. He described the devil as a sick, repulsive being with rotting flesh and having the personality of a crazy person. Neither Scott's verbal descriptions nor his drawings conformed to archetypal images of devils or angels. In addition, descriptions of heaven or hell were conspicuously missing from Scott's narrative and drawings. One would expect that such scenes would accompany descriptions of devils and angels because of their historic association with these beings in literature, art, and the popular press. This statement is not intended to deny the proposition that subconscious imagery plays a role in what is perceived by the experiencer. Rather, it is a rejection of the assumption that what Scott reported was simply a product of subconscious cultural conditioning. Scott displayed no interest in such beings prior to his experience, and his conception of the devil did not conform to the being he encountered.

I attempted to investigate Scott's life experience immediately prior to his NDE to ascertain whether his mental and emotional state at the time of the accident may have had a direct effect on the nature of his experience. When asked, Scott conceded that he had a "bad year." One of his teachers had adopted an adversarial relationship with Scott and frequently rebuked him before his classmates. Scott recalled being so angered by this constant humiliation that he retaliated by picking fights with other classmates. His mother remarked that throughout his first grade school year Scott would repeatedly come home and say, "I'm bad." Upon examination, the events that led Scott to feel this way were usually found to be normal mischief such as talking or drawing pictures during class. These events could have set the stage for the frightening aspect of his NDE, as Scott probably did carry some anger, guilt, frustration, and self-doubt into his experience, but it is very difficult to gauge whether these subconscious emotional conditions were sufficient to precipitate his encounter with the devil. During his interview, Scott appeared to be genuinely shocked and surprised by his 
confrontation with the devil. We cannot determine definitively whether Scott subconsciously projected his own distressing imagery or whether he witnessed some independent source of evil.

Another interesting observation in Scott's case relates to the accuracy of recall, particularly with regards to detailed imagery. While the structure, sequence, and affect of Scott's NDE have remained consistent over the five years since the initial event took place, recall of visual details appears to have been degraded by the passage of time. Two examples typify this observation. In an early account of his NDE told to his mother shortly after being discharged from the hospital, Scott reported that his escort was a female angel named Susan. By March 1999 he could not recall the form, gender, or name of this angel. His current memory was limited to a "presence" composed of warm light that radiated a sense of comfort and security. Another example is that in Scott's initial account, he mentioned that his uncle was wearing a gray suit when they met. However, recently Scott reported that his uncle was wearing bedclothes and was partially covered by a sheet. It is impossible to determine which version of these accounts is the more accurate, but it is clear that later descriptions differ from earlier accounts. This same effect can be seen by comparing original drawings of the devil and angel with those drawn more recently. Degradation of detail may be a function of the age at which the NDE is experienced, or it may represent a natural process correlated with the time elapsed since the NDE was experienced.

The elements and chronology of Scott's NDE are consistent with those reported by other experiencers. Out-of-body experiences, passage through a dark tunnel, meeting deceased relatives, and feeling secure in the presence of a being of light have been widely confirmed since Raymond Moody first reported them (1975). Details concerning the specific characteristics of core elements and the description of the devil are more unusual. Children's accounts are often informative simply because they report exactly what they see without great concern over the rational interpretation of their observations. A careful review of Scott's account reveals a number of statements that are convincing because of their naiveté. A couple of examples may illustrate this point. When attempting to describe the tunnel that he had passed through, Scott said that "it was like a tornado flat on its side instead of being straight up and down." When asked how he had moved through this tunnel, Scott replied that he was kind of "pushed and pulled" at the same time. Lastly, when I attempted to gain a description of the interior of the vortex, Scott simply shook his shoulders and said that he did not 
remember, but that it seemed to contain the voices and faces of everyone who had ever loved him.

Except for a remarkable recovery from the physical trauma of the accident, Scott has experienced no unusual aftereffects, such as synesthesia, electromagnetic effects, paranormal phenomena, or changes in physical sensitivities. Changes in values appear to be restricted to religious teachings and have already been noted. Scott's parents believe that their son has become very insightful and that he is far more caring in his relationships with family and peers. They also note that, prior to his NDE, Scott had been unusually impulsive, but this trait greatly diminished following his NDE.

As with many accounts from children, Scott's narrative was fragmentary and did not neatly conform to a logical sequence of events. Transitions between scenes and events were abrupt. His recollections of events were more like a slide show than a film clip. While we may speculate about the missing gaps in Scott's recall, reported scenes were informative, detailed, and contained a sense of authenticity. This case study supports the conclusion that children, like adults, experience frightening NDEs, and that such events can produce negative as well as positive aftereffects.

\section{Previous Reports of Frightening NDEs}

Frightening childhood NDEs challenge our sense of propriety. We equate childhood with innocence, and find it difficult to accept the possibility that children could be subject to such experiences. Scott was only 6 years old at the time of his automobile accident and was obviously surprised and shocked by his encounter with the devil.

Because of the infrequency of frightening NDEs, researchers know little of their nature and aftereffects. Early publications on NDEs were primarily concerned with establishing the phenomenological validity of the more common positive NDEs. Raymond Moody (1975), who first described NDEs, did not report any frightening experiences. In a later publication, Moody wrote that "in the mass of material I have collected no one has ever described to me a state like the archetypical hell" (Moody, 1977, p. 169).

The first investigator to focus the attention of the research community on frightening NDEs was cardiologist Maurice Rawlings (1978), who claimed that at least half of all NDEs contained frightening aspects. When subsequent researchers were unable to verify that 
frequency of negative cases, Rawlings theorized that many negative experiences converted themselves to positive ones, and that patients were biased in favor of recalling only the more positive aspects of their experiences.

Support for the existence of frightening NDEs come from an unexpected source. In a report of a nationwide Gallup poll on "verge of death" experiences in adult Americans, one chapter was devoted entirely to an examination of views about hell and to the occurrence of frightening NDEs, concluding that 1 percent of those surveyed reported "a sense of hell or torment" (Gallup and Proctor, 1982, p. 75). These experiences included featureless, sometimes forbidding faces; beings who are often merely present, but not at all comforting; a sense of discomfort, especially emotional or mental unrest; feelings of confusion about the experience; a sense of being tricked or duped into ultimate destruction; and fear about what the finality of death may involve.

English psychologist Margot Grey devoted a chapter of her book on NDEs to the topic of "negative" experiences, "usually characterised by a feeling of extreme fear or panic....emotional and mental anguish, extending to states of utmost desperation.... an intense feeling of loneliness during this period coupled with a great sense of desolation" (1985, p. 58). Grey also distinguished a type of experience she called "hell-like," which often included

a definite sense of being dragged down by some evil force, which is sometimes identified with the powers of darkness. At this stage, visions of wrathful or demonic creatures that threaten or taunt the individual are occasionally described, while others recount being attacked by unseen beings or figures which are often faceless or hooded. The atmosphere can be intensely cold or unbearably hot. It is not uncommon during this phase of the experience to hear sounds that resemble the wailing of 'souls' in torment, or alternatively to hear a fearsome noise like that of maddened wild beasts, snarling and crashing about. Occasionally, respondents will report a situation that resembles the archetypal hell in which the proverbial fire and an encounter with the devil himself are experienced. (1985, p. 58)

Based upon the contents of these accounts, Grey discerned a common sequence of events that included fear and a feeling of panic; an outof-body experience; entering a black void; sensing an evil force; and entering a hell-like environment.

P. M. H. Atwater (1992) suggested that frightening NDEs may be structured by the experiencer's subconscious mind, and that variations 
in details among different accounts reflect the operation of psychic rather than physical laws. Atwater found frightening NDEs to include lifeless or threatening apparitions; barren or ugly expanses; threats, screams, or silence; danger and the possibility of violence or torture; a feeling of cold; diminished light; attack or neglect producing surges of fear or anxiety; feeling challenged to defend one's very existence and struggling to stay alive; and occasional spontaneous flashbacks of threatening or terrifying scenes. Atwater claimed that unpleasant NDEs were "usually experienced by those who seem to have deeply suppressed or repressed guilts, fears, and angers, and/or those who expect some kind of punishment or accountability after death" (1992, p. 156).

Bruce Greyson and Nancy Evans Bush (1992) summarized a study of 50 frightening NDEs and identified three distinct types: phenomenologically prototypical NDEs interpreted as terrifying due to the loss of ego control; an experience of nonexistence or eternal void, in which the experiencer feels condemned to a featureless void for eternity; and experiences with hellish imagery, with descriptions of hellish environments, threatening demons, or feelings of being drawn into a dark pit. Reports of "hellish" experiences were quite variable in phenomenology, suggesting that some personal interpretations are of more archetypal imagery.

While Kenneth Ring found no cases of frightening NDEs in his original study (1980), and later conceded that such cases could account for 1 percent of all reported cases (1984), he most recently concluded "that frightening NDEs are themselves illusory phantasmagories thrown up by the ego in response to the threat of its own seeming imminent annihilation" (1994, p. 22), prompting Bush (1994) to object that he was trivializing the meaning and value of such experiences and to urge researchers to consider that even terrifying encounters contain valuable lessons for both individuals and society.

Although during the past decade near-death researchers have uncovered a surprising number of frightening NDEs, Rawlings' estimate that half of all NDEs contained frightening elements still appears to be an overestimation. Recent estimates by Atwater (personal communication, 1999) based on sample of 3000 adults and 277 children suggest an incidence rate of 15 percent for adults and 3 percent for children, significantly higher than the estimate of 1 percent made by early researchers. 


\section{Conclusion}

It is evident that Scott experienced a frightening NDE that had an impact on his subsequent behavior. Scott's interest in religious matters, particularly with regard to the existence of good and evil, may be the expression of a subconscious defense mechanism geared to providing information that could be used to improve his ability to respond in another frightening situation. A byproduct of this process may be the heightened awareness and insightfulness regarding moral issues that has been observed by Scott's parents. The noted reduction of impulsive behavior following the NDE may be the result of Scott's realization of vulnerability to forces beyond his control and to a realization that greater caution is required in the face of the unknown. It is also evident that the passage of time has degraded the recall of some visual details of Scott's experience. However, the structure and affect of the NDE have remained consistent.

Scott's negative experience did not seem to have been the product of cultural expectations, but there is some evidence that his prior emotional and psychological makeup may have set the stage for the adverse aspect of the experience. However, I was impressed by the apparent authenticity of Scott's experience and do not feel justified in dismissing the possibility that some component of the experience reflects interaction with an alternate reality.

This case supports the conclusion that frightening near-death experiences can, and do, occur to children. It is my opinion that Scott's unexpected confrontation with the devil led to a prolonged period of insecurity regarding his vulnerability to such encounters. Concern and vigilance over this prospect led to nightmares, restlessness, and prolonged anxiety. The passage of time does appear to have reduced Scott's concern over the prospect of future encounters, but emotional support from family members and healthcare providers also played a role in alleviating his anxiety. Frightening NDEs can produce adverse aftereffects of various intensity and duration. This observation has important implications to healthcare professionals in both pediatric and adult populations.

\section{References}

Atwater, P. M. H. (1992). Is there a hell? Surprising observations about the near-death experience. Journal of Near-Death Studies, 10, 149-160. 
Bush, N. E. (1994). The paradox of Jonah: Response to "Solving the riddle of frightening near-death experiences." Journal of Near-Death Studies, 13, 47-54.

Gallup, G., and Proctor, W. (1982). Adventures in immortality: A look beyond the threshold of death. New York, NY: McGraw-Hill.

Grey, M. (1975). Return from death: An exploration of the near-death experience. London, England: Arkana.

Greyson, B., and Bush, N. E. (1992). Distressing near-death experiences. Psychiatry, 55, 95-110.

Irwin, H. J., and Bramwell, B. A. (1988). The devil in heaven: A near-death experience with both positive and negative facets. Journal of Near-Death Studies, 7, $38-43$.

Lindley, J. H., Bryan, S., and Conley, B. (1981). Near-death experiences in a Pacific Northwest American population: The Evergreen Study. Anabiosis: The Journal of NearDeath Studies, 1, 104-124.

Moody, R. A. (1975). Life after life. Covington, GA: Mockingbird Books.

Moody, R. A. (1977). Reflections on life after life. St. Simon's Island, GA: Mockingbird Books.

Rawlings, M. (1978). Beyond death's door. Nashville, TN: Thomas Nelson.

Ring, K. (1980). Life at death: A scientific investigation of the near-death experience. New York, NY: Coward, McCann and Geoghegan.

Ring, K. (1984). Heading toward omega: In search of the meaning of the near-death experience. New York, NY: William Morrow.

Ring, K. (1994). Solving the riddle of frightening near-death experiences: Some testable hypotheses and a perspective based on $A$ course in miracles. Journal of Near-Death Studies, 13, 5-23. 